\title{
IMF Managing Director's Statement to the Development Committee, April 2020
}




\title{
INTERNATIONAL MONETARY FUND
}

\section{DEVELOPMENT COMMITTEE: THE MANAGING DIRECTOR'S WRITTEN STATEMENT}

\begin{abstract}
April 2020
The global coronavirus outbreak is a crisis like no other and poses daunting challenges for policymakers in many emerging market and developing economies (EMDEs), especially where the pandemic encounters weak public health systems, capacity constraints, and limited policy space to mitigate the outbreak's repercussions. A severe economic impact in the first half of 2020 is inevitable. Medium-term projections are clouded by uncertainty regarding the pandemic's magnitude and speed of propagation, as well as the longer-term impact of measures to contain the outbreak, such as travel bans and social distancing. However, most EMDEs are already suffering from disruptions to global value chains, lower foreign direct investment, capital outflows, tighter financing conditions, lower tourism and remittances receipts, and price pressures for some critical imports such as foods and medicines. Commodity exporters have to absorb, in addition, a sharp decline in export prices, notably for oil. Further, in most countries, the coronavirus outbreak is producing unanticipated health spending needs and revenue losses as activity slows. Coping with these challenges is especially difficult for countries with limited administrative capacity, tight external financing constraints and/or already high debt levels, and thus requires substantial support from the international community.
\end{abstract}

\section{ECONOMIC OUTLOOK AND RISKS}

The world economy was in a sluggish recovery before the coronavirus outbreak...

... and is now bound to suffer a severe recession in 2020.
The coronavirus pandemic struck the global economy in an already fragile state, weighed down by trade disputes, policy uncertainty, and geopolitical tensionseven though some signs of recovery had emerged at end-2019.

Prospects have deteriorated sharply with the spread of the COVID-19 pandemic. Countries that were affected early—such as China, South Korea, and Italy—have suffered large contractions in manufacturing activity and services, exceeding the losses recorded at the onset of the global financial crisis. Retrenchments in activity have been accompanied by a sharp repricing of financial assets amid rapidly deteriorating risk sentiment, large equity sell-offs, widening risk spreads, and reversals of portfolio flows to EMDEs. Many commodity prices have fallen sharply, notably for oil.

A large global contraction in the first half of 2020 is inevitable. Prospects thereafter depend on the intensity and efficacy of containment efforts, progress with developing vaccines and therapies, the extent of supply disruptions, shifts in spending patterns, the impact of tighter financial conditions on activity, and the size of the policy response. 


\section{Uncertainty surrounding the severity and length of the crisis is exceptionally high.}

Assuming the global economy starts recovering from the third quarter-as public health measures are scaled back and the impact of policy support materializes - the level of global GDP in 2020 would still decline substantially relative to 2019, with a contraction significantly worse than that in 2009 in the context of the global financial crisis (and compared to real growth of 2.9 percent in 2019). While the recovery is expected to pick up in 2021, by end-2021 global output would remain significantly below the pre-crisis trend.

Downside risks to the baseline scenario are large. The recovery could be slower and/or weaker than expected, for example because uncertainty about contagion lingers, and the measures to contain the spread of the virus trigger more lasting supply-chain disruptions and weaknesses in aggregate demand. A more persistent slump in business confidence could weaken investment by more than is currently projected, thus exerting a negative impact on trend growth. A protracted risk-off episode in financial markets would expose vulnerable corporate and sovereign borrowers to rollover risk, laying bare balance sheet fragilities that built up during the long phase of low global interest rates. Policy space to respond to the crisis is less than it was a decade ago, since in many countries monetary policy rates are already low and public debt is elevated.

\section{Emerging and developing economies are hit hard by both the domestic impact of the pandemic and cross-border spillovers...}

In EMDEs outside China and Iran, the increase in reported infection rates has generally lagged that of advanced economies. However, as the virus spreads, structural features such as weak public health systems, limited administrative capacity and sizeable informal sectors - that, among other things, complicate implementing social distancing measures-may leave many countries poorly placed to contain the pandemic, especially low-income developing countries (LIDCs) and fragile states.

Beyond the immediate domestic impact, global economic shockwaves triggered by the crisis affect EMDEs through depressed trade and impaired global supply chains, reversals of portfolio capital flows and tighter external financial conditions, and reduced foreign direct investment and remittances inflows. Many EMDEs import basic food stuffs and medicines-examples include Algeria, Egypt or Libya-which could become subject to supply-side constraints and trigger inflationary pressures. Conversely, low commodity prices will harm those EMDEs that rely on them for revenue, in particular, oil exporters such as Nigeria, Angola, or Ecuador.

Overall, real GDP in EMDEs is projected to contract by almost 1 percent in 2020, after 3.7 percent growth in 2019. Excluding China, real growth for the group in 2020 is expected to be -2 percent. 
... and often have

only limited macroeconomic policy space to respond to the pandemic.
Where macroeconomic policy space is constrained, options to mitigate the pandemic's economic repercussions are limited. This is true in particular for countries that lack access to external financing and/or have accumulated high levels of public debt: before the crisis' onset, about half of LIDCs were assessed to be at high risk of, or already in, debt distress, based on the IMF-World Bank debt sustainability assessments. As unanticipated health expenditures and lower revenues put pressure on fiscal balances, this share is bound to increase further.

For some EMDEs, financial stress is a distinct possibility, especially where falling commodity prices, tighter financial conditions, and strains on public and private sector balance sheets interact with pre-existing, underlying economic and financial vulnerabilities. Fighting twin funding and health crises would pose unprecedented challenges for policymakers in these countries.

\section{POLICY PRIORITIES}

The immediate priority is to minimize the pandemic's human toll and economic disruption.

Bold action from the international community is needed to help LIDCs cope with the pandemic and its economic and social repercussions.
The first priority must be to limit the human toll from the pandemic.

Policymakers must use all instruments at their disposal to slow the pandemic's spread and prevent overloading their health systems-the idea of a tradeoff between saving lives and saving livelihoods is a false dilemma.

Macroeconomic policy has a critical role to play in mitigating the economic and social fallout-and policymakers in both advanced economies and in EMDEs have already initiated important steps. Governments should increase health expenditures and provide targeted income support to the most affected people and firms-including through cash transfers, wage subsidies, tax relief, and loan maturity extensions-so as to limit bankruptcies and layoffs. Central banks should stand ready to combat disorderly market movements and ensure ample liquidity provision. To the extent that policy space and administrative capacities allow, they may also support activity by lowering borrowing costs for households and firms. Where macroprudential buffers are in place, these can be relaxed to mitigate the shocks' impact. Financial authorities should aim at preserving financial stability and banking system soundness to ensure that the financial system can support economic activity.

In countries with limited fiscal space, strict expenditure prioritization is necessary, with a focus on boosting health spending, strengthening social safety nets, and supporting the private sector. However, many LIDCs will not be able to stem the epidemic and its economic impact on their own. Substantial financial and technical assistance from donors will be needed, including through grants, emergency zero-interest rate loans, and debt service relief. In this context, President Malpass and I are calling on official bilateral creditors to suspend debt payments by IDA countries that request forbearance, to ease liquidity strains and create space for tackling the challenges posed by the pandemic. 


\author{
Multilateral \\ cooperation and \\ coordination are \\ indispensable for \\ an effective crisis \\ response.
}

Global cooperation is essential for global public health needs-from procurement of medical supplies to development of vaccines and treatments. It is critical that governments resist protectionist measures that exacerbate disruptions to global value chains and amplify uncertainty. In particular, they should refrain from restricting exports of necessary food and medical products. In the area of macroeconomic policy, a coordinated fiscal and monetary stimulus would help boost confidence and provide stability to the world economy. Swap lines by major central banks are critical to avoid liquidity crunches in key financial markets and to ensure smooth trade financing.

\section{IMF SUPPORT}

The IMF is using all its instruments to the fullest to help members combat the crisis.
The IMF is putting all its resources in the service of the global fight against the pandemic and its economic, social, and financial repercussions, in close cooperation with other international financial institutions and development partners.

To this end, the IMF is deploying its flexible emergency response toolkit-the Rapid Financing Instrument (RFI) and the Rapid Credit Facility (RCF)—to quickly help countries with urgent balance of payments needs as a result of the crisis. The RFI is available to all member countries, while the concessional RCF provides zero interest loans to PRGT-eligible members. Both provide assistance without the need for a fully fleshed out economic program. As per April 13, the IMF has received 74 such requests for emergency financing, more requests are expected in the coming weeks. The IMF has also temporarily doubled the amounts available to countries under the emergency response facilities in light of the pandemic.

The IMF's Catastrophe Containment and Relief Trust (CCRT) can provide grants to the poorest countries to pay off debt service to the IMF, thus freeing up resources for containment and mitigation of the pandemic. Earlier this week, the IMF Executive Board approved relief for 25 countries on obligations falling due until mid-October. We are working closely with bilateral donors to further enlarge the CCRT's resources and extend the duration of this relief.

Emergency financing can pave the way for new IMF-supported programs with larger loans, drawing on the IMF's $\$ 1$ trillion lending capacity. At this juncture the IMF has 39 ongoing arrangements - both disbursing and precautionarywith combined commitments of about $\$ 160$ billion. Augmenting these arrangements where program implementation is on-track is another option for providing financing rapidly. Moreover, the IMF is exploring options to offer members with very strong policies a short-term liquidity line, with a view to granting predictable and renewable access to IMF resources. 
While combatting the pandemic's impact takes precedence for now, other policy priorities remain on the agenda.
Beyond lending, the IMF is helping its members assess the macroeconomic implications of the outbreak. It provides policy advice on measures to fight the crisis and is reprioritizing its capacity development program to this end. Moreover, the IMF will continue to play its role at the core of the global financial safety net, facilitating and coordinating support from other International Financial Institutions, Regional Financing Arrangements, and bilateral donors. The IMF will also explore further options for creditor coordination in order to facilitate comprehensive and fair debt restructuring and restore debt sustainability.

Beyond the immediate efforts to fight the pandemic and its impact, the IMF will continue to work toward a more resilient and sustainable global economy. At this juncture, the IMF is prioritizing its work to help its members respond to the crisis. However, key challenges, such as containing the economic and financial repercussions of climate change, combatting debt vulnerabilities, aiding states in fragile situations, and supporting the modernization of the rules-based global trade system, will remain high on the IMF's agenda. 